\title{
The diagnostic value of modified systemic Inflammation score in predicting post-operative outcomes of cutaneous melanoma patients who underwent isolated limb perfusion
}

\author{
Şevket Barış Morkavuk ${ }^{1^{*}} \mathbb{D}$, Serdar Çulcu² Ebru Esen $^{3}$ and Ali Ekrem Ünal ${ }^{4}$
}

\begin{abstract}
Background: In-transit metastasis is considered a locoregional disease in cutaneous melanoma (CM) patients. Isolated limb perfusion (ILP) is among the treatment options in selected cases. The aim of this study was to determine the success of pre- and post-perfusion mSIS values in predicting the potential complications and the prognosis of the disease by investigating the early and long-term results of mSIS values calculated before and after ILP in CM cases with in-transit metastases.
\end{abstract}

Materials and methods: Patients who underwent ILP within the period from 2014 to 2020 in our department were retrospectively scanned. A total of 20 patients were found to undergo ILP. The scores obtained from modified inflammation score (mSIS) were formulated according to albumin (Alb) and lymphocyte to monocyte ratio (LMR) scores.

Results: The mean follow-up time was 20.47 months. Complications requiring surgical intervention developed in three patients. According to the Wieberdink local toxicity classification, the majority (70\%) of the patients were found to be grade II. Based on pre-perfusion mSIS values, 8 patients were classified as mSIS 0 while six patients were classified as mSIS 1 and 2. Based on post-perfusion mSIS values, 14 patients and one patient were classified as mSIS 2 (70\%) and mSIS 0, respectively. Accordingly, univariate analysis showed that mSIS 1 and mSIS 2 were negative prognostic factors for mean survival in the pre-perfusion period (HR 0.162, 95\% Cl 0.036-0.729; $p=0.018$ and HR: $0.223,95 \%$ Cl 0.049-1.019; $p=0.053$ ) whereas albumin (Alb) and lymphocyte to monocyte ratio (LMR) were not independent prognostic factors for mean survival.

Conclusion: The mSIS values calculated in the pre-perfusion period can give an opinion about the OS of the patients whereas post-perfusion mSIS values may predict potential surgical complications and local toxicities.

Keywords: Isolated limb perfusion, Modified systemic inflammation score, Cutaneous melanoma, Lymphocyte-tomonocyte ratio, Albumin

\footnotetext{
*Correspondence: drsbmor@yahoo.com

1 Department of Surgical Oncology, Ankara City Hospital, Ankara, Turkey

Full list of author information is available at the end of the article Synopsis: The modified inflammation score values calculated in the pre-perfusion period can give an opinion about the overall survival of the patients whereas post-perfusion modified inflammation score values may predict potential surgical complications and local toxicities.
}

\section{Background}

Cutaneous melanoma $(\mathrm{CM})$ is a skin malignancy originating from melanocytes-cells found in the basal membrane of epidermis that determine skin color. In comparison to other skin cells, there are 1500 melanocytes per square millimeter and they undergo mitosis less than twice a year. Therefore, the incidence of cutaneous original author(s) and the source, provide a link to the Creative Commons licence, and indicate if changes were made. The images or other third party material in this article are included in the article's Creative Commons licence, unless indicated otherwise in a credit line to the material. If material is not included in the article's Creative Commons licence and your intended use is not permitted by statutory regulation or exceeds the permitted use, you will need to obtain permission directly from the copyright holder. To view a copy of this licence, visit http://creativecommons.org/licenses/by/4.0/. The Creative Commons Public Domain Dedication waiver (http://creativeco mmons.org/publicdomain/zero/1.0/) applies to the data made available in this article, unless otherwise stated in a credit line to the data. 
melanoma is quite low [1]. It accounts for less than $4 \%$ of all skin cancers; however, this low incidence rate is inversely proportional to prognosis. Cutaneous melanoma causes $80-85 \%$ of all skin cancer-related deaths [2]. Cancer statistics of 2020 shows that $1,806.590$ new cases of cancer have been diagnosed in the United States and 100.350 of them are malignant melanoma (5.5\%). While 606,520 individuals died due to cancer, the number of deaths due to malignant melanoma is 6850 [3]. It has higher mortality rates in comparison with incidence which is attributed to both, the histopathological features and the advanced stage of the disease at the time of diagnosis.

In-transit metastasis occurs in $4-11 \%$ of patients with cutaneous melanoma 13-16 months after the initial diagnosis [4]. In-transit metastasis is defined as the presence of cutaneous melanoma cells in the cutaneous and subcutaneous lymphatic ducts between the primary tumor focus and the lymph nodes where the tumor is drained [5]. In the American Joint Committee on Cancer (AJCC) guideline, in-transit metastasis is considered a locoregional disease. Based on the tumor, node, and metastasis (TNM) classification system, they are included either in stage IIIB (no lymph node metastasis) or stage IIIC (lymph node metastasis). The overall 5-year survival rate ranges from 24 to $54 \%$ compared to lymph node metastasis and the median survival is 19 months [6]. In the presence of a limited number of metastatic lesions, treatment of melanoma includes surgical resection, radiotherapy, chemotherapy, immunotherapy [interleukin-2 (IL-2), granulocyte-macrophage colony-stimulating factor (GMCSF), ipilimumab, tremelimumab, interferon- $\alpha$ ), and targeted therapies (BRAF inhibitors; vemurafenib, dabrafenib, and MEK inhibitor) [7]. Since it is considered a locoregional disease, isolated limb perfusion (ILP) is among the treatment options in selected cases. The ILP method was first described by Creech and Ryan in 1958 [8]. In this technique, chemotherapy doses administered at the site between the primary tumor and the draining lymph node can be 25 times higher than those used for systemic therapy, and systemic toxicity is also avoided. As in hyperthermic intraperitoneal chemotherapy (HIPEC), the efficacy of chemotherapeutic agents is improved with regional hyperthermia in the ILP technique. Complete response is achieved in $40 \%$ of patients within a period from 3 to 6 months whereas there is a partial response in $40 \%$ and no response in $20 \%$ [9]. It is a limb-sparing procedure since it can be re-performed in cases with a complete response and partial response. However, it is associated with non-negligible morbidity (73\% for erythema, $17 \%$ for edema, $2 \%$ for skin necrosis and compartment syndrome, and $0.6 \%$ for limb loss) and mortality rates $[10]$.
Virchow was the first author who reported in 1863 that systemic inflammation has an important role in cancer pathogenesis and progression [11]. Studies have shown that chronic inflammation stimulates malignant cells to increase proliferation, angiogenesis, and thus, metastasis. Serum-based inflammation parameters [e.g., platelet to lymphocyte ratio (PLR), lymphocyte to monocyte ratio (LMR), neutrophil to lymphocyte ratio (NLR)] have been shown to be prognostic factors in various cancer types [12]. Similarly, C-reactive protein (CRP), a positive acutephase protein (APPs), and albumin (Alb), a negative APP, are known to be inflammation biomarkers. Both parameters are used in an inflammation-based scoring system known as the modified Glasgow prognostic score (mGPS). Chang et al. described a modified systemic inflammatory scoring (mSIS) system using both serum Alb and LMR. They reported that this scoring system was superior to the traditional systemic inflammation scoring system (SIS) in renal cell cancer prognosis and gave more accurate results [13].

The aim of this study was to determine the success of pre- and post-perfusion mSIS scores in predicting the potential complications and the prognosis of the disease by investigating the early and long-term results of $\mathrm{mSIS}$ score calculated before and after ILP in CM cases with in-transit metastases.

\section{Materials and methods}

\section{Study population}

This study was conducted under approval of Ankara City Hospital ethics committee. Patients who underwent ILP within the period from 2014 to 2020 in the Ankara University Faculty of Medicine Department of Surgical Oncology were retrospectively observed. A total of 30 patients were found to undergo ILP. Two patients with a pathological diagnosis of sarcoma and eight patients with no pre-and post-ILP inflammation parameters in laboratory tests were excluded from the study. A total of 20 patients were included in the study.

\section{Establishment of the modified SIS (mSIS)}

The scores obtained from mSIS were formulated according to Alb and LMR scores. Patients were assigned to mSIS 0 if Alb was $\geq 4.0 \mathrm{~g} / \mathrm{dL}$ and LMR was $\geq 3.4, \mathrm{mSIS} 1$ if Alb was $<4.0 \mathrm{~g} / \mathrm{dL}$ or LMR was 3.4, and mSIS 2 if Alb was $4.0 \mathrm{~g} / \mathrm{dL}$ and LMR was 3.4 [14].

\section{Description of ILP technique and post-operative patient management}

Computed tomography angiography (CTA) and venous Doppler ultrasonography (USG) were performed preoperatively in all patients, who would undergo ILP, to evaluate the vascular anatomy. The presence of collateral 
vascular formation was detected via CTA, and thus, the uncontrolled delivery of chemotherapy drug into systemic circulation was prevented. The risk of venous complications due to an existing venous thrombosis was minimized with Doppler USG. In the lower extremities, the femoral artery and vein were used for tumors located in the thigh and its distal area, and iliac artery and vein were used for tumors located in the inguinal region. Axillary artery and vein were used in upper extremity lesions. Arteriovenous structures were suspended and 5000 international units (IU) of heparin was administered as a bolus before distal and proximal clamping. After waiting for 3 min, arteriotomy and venotomy were performed. Then, the artery and vein were cannulated using a $12 \mathrm{~F}$ catheter. Melphalan of $100 \mathrm{mg} / \mathrm{kg}$ and $50 \mathrm{mg} / \mathrm{kg}$ was titrated for the lower and upper extremities, respectively. The perfusion concentrate was calculated as $10 \mathrm{mg}$ melphalan/L for the upper extremity and $12 \mathrm{mg}$ melphalan/L for the lower extremity. The melphalan + fluid combination was infused into the limb at $40^{\circ}$ for $60 \mathrm{~min}$. The perfusion rate was kept between $200 \mathrm{~mL} / \mathrm{min}$ and $300 \mathrm{~mL} / \mathrm{min}$ to remove cytotoxic agents released from the tumor tissue. The perfusate was passed through the hemofilter for 15 min at the end of the perfusion to avoid systemic toxicity. Following the procedure, cannulae were removed and then, arteriotomy and venotomy incisions were sutured. On the first post-operative day, the perfused limbs were covered by cotton bandages to be kept warm to prevent the risk of vascular contraction. Color and heart rate were checked every $2 \mathrm{~h}$. Doppler USG was utilized in suspected cases.

\section{Classification of surgical complications and assessment of local toxicity}

Clavien-Dindo classification was used for scoring postoperative surgical complications [15]. The patients were scored from 1 to 5 according to the complications. Postperfusion local toxicity was evaluated using the scale developed by Wieberdink et al. in 1992 [16]. Patients were evaluated and scored for local toxicity from the beginning of perfusion to the third post-operative month.

\section{Study design}

The pre-and post-ILP mSIS scores of the patients were calculated using Alb and LMR values. The correlation of pre-and post-ILP mSIS values with post-operative surgical complications and local toxicity was evaluated. Furthermore, the association between the mSIS values and the prognosis, overall survival (OS) rates, histopathological data, and demographic data of the disease was investigated.

\section{Statistical analysis}

Statistical analyses were performed using SPSS Statistics for Windows, Version 22.0. G-power v3.1.9.4 was used for study power analysis. Pearson's chi-square test and Fisher's exact test were used for evaluation of nominal data of each group whereas Student's $t$ test was used for parametric data and Mann-Whitney U test for non-parametric data. One-way ANOVA, Kruskal Wallis, and post hoc multiple comparison (Bonferroni) tests were used for the analysis of multiple groups. The paired sample $\mathrm{t}$-test was used to test the significance of the difference between the arithmetic means of the two dependent parametric groups whereas the significance of the difference between the arithmetic medians of the two dependent non-parametric groups was tested using the Wilcoxon signed-rank test. Univariate or multivariate death hazard ratios (HRs) were calculated with the Cox regression model. The Kaplan-Meier method was utilized for the calculation of OS. A $p$ value of $<0.05$ was considered statistically significant. When the Power analysis is done for the correlation analysis, the power of the study is calculated as 0.896 when the effect size conventions is taken as 0.5 , the power of the study is calculated as 0.758 when the effect size conventions is taken as 0.3 , and the power of the study is calculated as 0.589 when the effect size conventions is taken as 0.1 .

\section{Results \\ Patient characteristics}

This study evaluated a total of 20 patients undergoing ILP due to CM. The gender distribution of the patients was homogeneous (10 males and 10 females). The mean age of all patients included in the study was 49.55 (range 16-78) years. The mean age of male and female patients were 45.70 (range 16-75) years and 53.40 (range 19-78) years, respectively. A total of 14 patients, who were being followed and treated with the diagnosis of cutaneous melanoma in an external center, were referred to our clinic for ILP since in-transit metastasis developed during this period. The anatomical origin of CM was lower extremity $(70 \%)$ in 14 patients and upper extremity in six patients (30\%). Regardless of the extremity, left lateralization was observed in $55 \%(n=11)$ of the patients. The lesion was in the thigh in $42.9 \%(n=6)$ of patients with $\mathrm{CM}$ originating from the lower extremity. The lesions were found to be evenly distributed in the finger and forearm area among patients with CM originating from the upper extremity. Early mortality (first 30 days) was observed in two patients. Only one patient died from a pulmonary embolism before discharge. Six patients were alive while a total of 14 patients died due to primary cancer or secondary causes during the follow-ups. The mean 
follow-up time was 20.47 (range 0-82.3) months. Complications requiring surgical intervention developed in three patients. According to the Wieberdink local toxicity classification, the majority $(70 \%)$ of the patients were found to be grade II. There were no patients developing deep tissue damage or requiring amputation. The mean carcinoembryonic antigen (CEA) value of the patients included in the study was $1.51 \mathrm{ng} / \mathrm{mL}$ (range 0.16-3.63) and the mean alpha-fetoprotein (AFP) value was $3.09 \mathrm{ng} /$ $\mathrm{mL}$ (range 0.92-8.22). Table 1 presents the demographic and histopathological distribution of all patients in detail.

\section{Evaluation of pre- and post-perfusion mSIS parameters}

Homogeneous distribution was observed in mSIS values measured before ILP. Eight patients were classified as mSIS 0 while six patients were classified as mSIS 1 and 2. Based on post-perfusion mSIS values, 14 patients and one patient were classified as mSIS 2 (70\%) and mSIS 0 , respectively. While the pre-perfusion mean Alb value was $3.80 \mathrm{~g} / \mathrm{dL}$ (range 1.90-4.75), this value was found to be $2.95 \mathrm{~g} / \mathrm{dL}$ after perfusion (range 1.74-4.00). This difference was found to be statistically significant $(p<0.01)$. There was no statistically significant difference between the pre-and post-perfusion median LMR values (3.59 vs 2.56, $p=0.654$ ). The pre-perfusion mean hemoglobin (Hgb) value was $13 \mathrm{~g} / \mathrm{dL}$ (range 7.90-18.60) whereas this value was calculated as $10.61 \mathrm{~g} / \mathrm{dL}$ after perfusion (range $8-13.80)$. This decrease was statistically significant $(p<$ 0.01 ). Similar to LMR, there was no significant difference between pre- and post-perfusion median CRP values (3.6 vs 7.27, $p=0.455)$. In other words, perfusion did not lead to a significant increase in LMR and CRP (Table 2).

\section{Comparison of pre- and post-perfusion mSIS groups with clinicopathological parameters}

The evaluation of pre-perfusion mSIS groups according to gender, affected limb, lateralization, and location distribution showed no statistically significant difference. There was no significant difference in the distribution of the groups according to mean and median values of age, pre-perfusion $\mathrm{Hgb}$, pre-perfusion CRP, lymph node metastasis, CEA, AFP, and hospitalization time. However, a statistically significant difference was observed in the distribution of mSIS groups according to pre-perfusion Alb value, pre-perfusion LMR value, and follow-up times. The median follow-up time of patients was 21.21 months in the pre-perfusion mSIS 0 group whereas this time was 17.61 months in mSIS 1 and 3.71 months in $\mathrm{mSIS} 2$. Although this difference may seem like an inverse ratio at first glance, it will be understood to be significant when the OS rates, which are mentioned in the following chapters, are examined. Because the OS rate decreases as the mSIS value increases. This significant difference was due to the difference in the follow-up time of patients in the mSIS 0 and mSIS 2 groups $(p=0.034)$.

The evaluation of post-perfusion mSIS groups according to gender, affected limb, lateralization, and location distribution showed no statistically significant difference. There was no statistically significant difference in the distribution of the groups according to the mean and median values of the following variables: age, post-perfusion Alb, Hgb, CRP, CEA, AF, and follow-up times. On the other hand, a statistically significant difference was found in the distribution of post-perfusion mSIS groups according to lymph node metastasis, number of lymph node metastases, and hospitalization time. While 13 of 16 patients with lymph node metastases were in the postperfusion mSIS 2 group, only one patient in the postperfusion mSIS 0 group had lymph node metastasis $(p=$ $0.035)$. The median hospitalization time of the patients was 6 days in mSIS 2 group, 4 days in mSIS 1 , and 3 days in $\operatorname{mSIS~} 0(p=0.032)$ (Table 3$)$.

\section{Relevance of pre- and post-perfusion mSIS for surgical complications and local toxicity}

The surgical complication and local toxicity rates of the pre- and post-perfusion mSIS groups were evaluated. There was no statistically significant difference in the distribution of pre-perfusion mSIS groups according to Clavien-Dindo complication classification and Wieberdink local toxicity classification $(p=0.188$ and $p=$ 0.786). Similarly, no statistically significant difference was observed in the distribution of post-perfusion mSIS groups according to surgical complication and local toxicity classifications $(p=0.555$ and $p=0.110)$. However, in post-perfusion mSIS groups, all patients having grade III and IV complications according to the Clavien-Dindo classification were found to be in the mSIS 2 group. Similarly, 10 of 14 patients with grade II local toxicity and all three patients with grade III local toxicity according to the Wienberdink scale were also in the mSIS 2 group (Table 4).

\section{The association between the early mortality and OS rates according to the pre- and post-perfusion $\mathrm{mSIS}$ scores}

Early mortality and OS rates of the patients, who were categorized according to their pre- and post-perfusion mSIS scores, were analyzed. There was no statistically significant difference in the distribution of pre- and postperfusion mSIS groups according to early mortality ( $p=$ 0.477 and 0.672 ). Two patients with early mortality were both in the pre-perfusion mSIS 1-2 and post-perfusion mSIS 1-2 groups. The OS curves were generated by Kaplan-Meier analysis. There was a statistically significant correlation between the pre-perfusion mSIS groups (log-rank chi-square $=7.32, p=0.026)$ whereas there 
Table 1 Demographic and histopathological distrubition of the patients

\begin{tabular}{|c|c|}
\hline Age, year, mean $\pm S D$, range & $49.55 \pm 19.06(16-78)$ \\
\hline \multicolumn{2}{|l|}{ Gender: $n(\%)$} \\
\hline Male & $10(\% 50)$ \\
\hline Female & $10(\% 50)$ \\
\hline \multicolumn{2}{|l|}{ Primary/secondary case: $n(\%)$} \\
\hline Primary & $6(\% 30)$ \\
\hline Secondary & $14(\% 70)$ \\
\hline \multicolumn{2}{|l|}{ Location: $n(\%)$} \\
\hline Upper limb & $6(\% 30)$ \\
\hline Lower limb & $14(\% 70)$ \\
\hline \multicolumn{2}{|l|}{ Lateralization: $n(\%)$} \\
\hline Left & $11(\% 55)$ \\
\hline Right & $9(\% 45)$ \\
\hline \multicolumn{2}{|l|}{ Metastatic node status: $n(\%)$} \\
\hline Absent & $4(\% 20)$ \\
\hline Present & $16(\% 80)$ \\
\hline Metastatic node, number, mean $\pm S D$, range & $1.51 \pm 1.04(0-6)$ \\
\hline \multicolumn{2}{|l|}{ Pre-perfusion mSIS groups: $n(\%)$} \\
\hline mSIS 0 & $8(\% 40)$ \\
\hline mSIS 1 & $6(\% 30)$ \\
\hline mSIS 2 & $6(\% 30)$ \\
\hline \multicolumn{2}{|l|}{ Post-perfusion mSIS groups: $n(\%)$} \\
\hline mSIS 0 & $1(\% 5)$ \\
\hline mSIS 1 & $5(\% 25)$ \\
\hline mSIS 2 & $14(\% 70)$ \\
\hline \multicolumn{2}{|l|}{ Clavien-Dindo classification, $n(\%)$} \\
\hline Grade I & $12(\% 60)$ \\
\hline Grade II & $3(\% 15)$ \\
\hline Grade III & $2(\% 10)$ \\
\hline Grade IV & $2(\% 10)$ \\
\hline Grade V & $1(\% 5)$ \\
\hline \multicolumn{2}{|l|}{ Wieberdink toxicity score, $n(\%)$} \\
\hline Grade I & $3(\% 15)$ \\
\hline Grade II & $14(\% 70)$ \\
\hline Grade III & $3(\% 15)$ \\
\hline Alpha fetoprotein, $\mathrm{ng} / \mathrm{mL}$, mean $\pm S D$, range & $3.09 \pm 2(0.92-8.22)$ \\
\hline Carcinoembryonic antigen, $\mathrm{ng} / \mathrm{mL}$, mean $\pm \mathrm{SD}$, range & $1.51 \pm 1.04(0.16-3.63)$ \\
\hline Lenght of hospital stay, day, mean $\pm S D$, range & $5.10 \pm 1.51(3-8)$ \\
\hline \multicolumn{2}{|l|}{ Early mortality } \\
\hline Absent & $18(\% 90)$ \\
\hline Present & $2(\% 10)$ \\
\hline - before discharge (due to pulmonary embolism) & 1 \\
\hline - after discharge & 1 \\
\hline Follow-up time, month, mean $\pm S D$, range & $20.47 \pm 21.87(0-82.3)$ \\
\hline \multicolumn{2}{|l|}{ Survive } \\
\hline Live & $6(\% 30)$ \\
\hline Death & $14(\% 70)$ \\
\hline
\end{tabular}

${ }^{x}$ Early mortality (first 30 days): observed in two patients. One patient died from a pulmonary embolism before discharge 
Table 2 Pre-perfusion and post-perfusion, analysis of dependent variables

\begin{tabular}{|c|c|c|c|}
\hline Variables & Pre-perfusion & Post-perfusion & $p$ value \\
\hline $\begin{array}{l}\text { Albumin, g/dL, mean } \\
\pm S D\end{array}$ & $3.80 \pm 0.69$ & $2.95 \pm 0.60$ & $<0.01^{\mathrm{t}}$ \\
\hline median (range) & $3.95(1.9-4.75)$ & $3.05(1.74-4)$ & \\
\hline LMR, mean \pm SD & $3.63 \pm 1.73$ & $4.15 \pm 4.93$ & \\
\hline median (range) & $3.59(1.14-6.77)$ & $2.56(0.61-23)$ & $-0.654^{z}$ \\
\hline $\mathrm{Hgb}, \mathrm{g} / \mathrm{dL}$, mean $\pm \mathrm{SD}$ & $13 \pm 2.47$ & $10.61 \pm 1.74$ & \\
\hline median (range) & $13(7.9-18.6)$ & 10.95(8-13.8) & $<0.01^{\mathrm{t}}$ \\
\hline$C R P, m g / L$, mean $\pm S D$ & $17.27 \pm 45.23$ & $13.04 \pm 18.87$ & \\
\hline median (range) & $3.6(1.68-201)$ & $7.27(1-85)$ & $-0.455^{z}$ \\
\hline
\end{tabular}

$t$ paired samples $t$ test, $Z$ Wilcoxon signed-ranks test

was no statistically significant difference between the mean survival curves of the post-perfusion mSIS groups (log-rank chi-square $=1.786, p=0.409)$ (Fig. 1). These findings were confirmed with the Cox-Regression test. Table 5 shows the univariate and multivariate survival analysis of mSIS and its components in detail. Accordingly, univariate analysis showed that mSIS 1 and mSIS 2 were negative prognostic factors for mean survival in the pre-perfusion period (HR 0.162, 95\% CI 0.036-0.729; $p=0.018$ and HR 0.223, 95\% CI 0.049-1.019; $p=0.053$ ) whereas Alb and LMR were not independent prognostic factors for mean survival (Table 5).

\section{Discussion}

Cutaneous melanoma is a rare type of skin cancer with high mortality. Its incidence has been dramatically increased in recent years. This increase is reported to be $33 \%$ for men and $23 \%$ for women [17]. Cutaneous melanoma is a malignancy with a highly poor prognosis. The loss of average life expectancy of a person diagnosed with cancer is about 16.6 years whereas this loss is 20.4 years in cutaneous melanoma [18]. Surgical treatment is performed only for palliative purposes in patients with advanced-stage cutaneous melanoma and does not contribute to survival. In-transit metastasis is considered as a locoregional disease in both National Comprehensive Cancer Network (NCCN) and AJCC guidelines and is considered to be stage III. Therefore, systemic treatment is supported with surgical interventions such as local excision or ILP, which is a routine procedure in our clinic.

Factors affecting early and long-term results of surgical intervention have been investigated in many studies and undoubtedly, serum-based inflammatory parameters and scoring systems developed based on them have recently come to the fore. This scoring system, which is called systemic inflammatory response, has been replaced by $\mathrm{mSIS}$ with the inclusion of new parameters over time. The present study investigated the early and
Table 3 Relationship between pre-perfusion and post-perfusion mSIS groups with clinico-pathological factors

\begin{tabular}{|c|c|c|c|c|}
\hline \multirow[t]{2}{*}{ Variables } & \multicolumn{2}{|l|}{ Pre-perfusion } & \multicolumn{2}{|c|}{ Post-perfusion } \\
\hline & Data & $p$ value & Data & $p$ value \\
\hline \multicolumn{5}{|c|}{ Age, year, mean \pm SD } \\
\hline mSIS 0 & $47.88 \pm 21.74$ & & 78 & \\
\hline mSIS 1 & $50.50 \pm 19.18$ & $p=0.954^{F}$ & $55.20 \pm 23.96$ & $p=0.198^{F}$ \\
\hline mSIS 2 & $50.83 \pm 18.54$ & & $45.50 \pm 16.19$ & \\
\hline \multicolumn{5}{|l|}{ Gender: $n$} \\
\hline \multicolumn{5}{|l|}{ Male } \\
\hline mSIS 0 & 4 & & 0 & \\
\hline mSIS 1 & 3 & & 3 & \\
\hline mSIS 2 & 3 & $p=1.00^{\times 2}$ & 7 & $p=0.549^{2}$ \\
\hline \multicolumn{5}{|l|}{ Female } \\
\hline mSIS 0 & 4 & & 1 & \\
\hline mSIS 1 & 3 & & 2 & \\
\hline mSIS 2 & 3 & & 7 & \\
\hline \multicolumn{5}{|c|}{ Primary/secondary case: $\boldsymbol{n}$} \\
\hline \multicolumn{5}{|c|}{ Primary } \\
\hline mSIS 0 & 2 & & 0 & \\
\hline mSIS 1 & 2 & & 2 & \\
\hline mSIS 2 & 2 & $p=0.924^{2}$ & 4 & $p=0.712^{\times 2}$ \\
\hline \multicolumn{5}{|c|}{ Secondary } \\
\hline mSIS 0 & 6 & & 1 & \\
\hline mSIS 1 & 4 & & 3 & \\
\hline mSIS 2 & 4 & & 10 & \\
\hline \multicolumn{5}{|c|}{ Location: $n$} \\
\hline \multicolumn{5}{|c|}{ Upper limb } \\
\hline mSIS 0 & 2 & & 0 & \\
\hline mSIS 1 & 1 & & 2 & \\
\hline mSIS 2 & 3 & $p=0.418^{x^{2}}$ & 4 & $p=0.712^{X^{2}}$ \\
\hline \multicolumn{5}{|c|}{ Lower limb } \\
\hline mSIS 0 & 6 & & 1 & \\
\hline mSIS 1 & 5 & & 3 & \\
\hline mSIS 2 & 3 & & 10 & \\
\hline \multicolumn{5}{|c|}{ Lateralization: $\boldsymbol{n}$} \\
\hline \multicolumn{5}{|c|}{ Left } \\
\hline mSIS 0 & 4 & & 1 & \\
\hline mSIS 1 & 3 & & 2 & \\
\hline mSIS 2 & 4 & & 8 & \\
\hline \multicolumn{5}{|l|}{ Right } \\
\hline mSIS 0 & 4 & & 0 & \\
\hline mSIS 1 & 3 & & 3 & \\
\hline mSIS 2 & 2 & $p=0.790^{\times 2}$ & 6 & $p=0.522^{x^{2}}$ \\
\hline \multicolumn{5}{|c|}{ Metastatic node status: $n$} \\
\hline \multicolumn{5}{|c|}{ Absent } \\
\hline mSIS 0 & 1 & & 0 & \\
\hline mSIS 1 & 2 & & 3 & \\
\hline mSIS 2 & 1 & $p=0.610^{x^{2}}$ & 1 & $p=0.035^{x^{2}}$ \\
\hline \multicolumn{5}{|l|}{ Present } \\
\hline mSIS 0 & 7 & & 1 & \\
\hline
\end{tabular}


Table 3 (continued)

\begin{tabular}{|c|c|c|c|c|}
\hline \multirow[t]{2}{*}{ Variables } & \multicolumn{2}{|l|}{ Pre-perfusion } & \multicolumn{2}{|l|}{ Post-perfusion } \\
\hline & Data & $p$ value & Data & $p$ value \\
\hline mSIS 1 & 4 & & 2 & \\
\hline $\mathrm{mSIS} 2$ & 5 & & 13 & \\
\hline \multicolumn{5}{|c|}{ Metastatic node, number, mean \pm SD } \\
\hline mSIS 0 & $2.63 \pm 1.76$ & $p=0.560^{\mathrm{F}}$ & 5 & $p=0.05^{\mathrm{F}}$ \\
\hline mSIS 1 & $1.83 \pm 1.47$ & & $1 \pm 1.41$ & \\
\hline mSIS 2 & $3.88 \pm 2.36$ & & $2.86 \pm 1.70$ & \\
\hline \multicolumn{5}{|c|}{ Lymphocyte to monocyte ratio (LMR), mean \pm SD } \\
\hline mSIS 0 & $5.05 \pm 1.14$ & $p=0.001^{\mathrm{F}}$ & 7 & $p=0.015^{\mathrm{H}}$ \\
\hline mSIS 1 & $3.39 \pm 1.42$ & & $8.60 \pm 8.15$ & \\
\hline mSIS 2 & $1.97 \pm 0.98$ & & $2.36 \pm 1.85$ & \\
\hline \multicolumn{5}{|c|}{ Albumin, $\mathrm{g} / \mathrm{dL}$, mean $\pm \mathrm{SD}$} \\
\hline mSIS 0 & $4.33 \pm 0.25$ & $p<0.01^{\mathrm{F}}$ & 4 & $p=0.1^{\mathrm{F}}$ \\
\hline mSIS 1 & $3.93 \pm 0.33$ & & $3.16 \pm 0.64$ & \\
\hline mSIS 2 & $2.96 \pm 0.57$ & & $2.80 \pm 0.52$ & \\
\hline \multicolumn{5}{|c|}{ C-reactive protein, $\mathrm{mg} / \mathrm{L}$, mean $\pm \mathrm{SD}$} \\
\hline mSIS 0 & $4.72 \pm 3.84$ & $p=0.196^{\mathrm{H}}$ & 1.5 & $p=0.303^{\mathrm{H}}$ \\
\hline mSIS 1 & $3.12 \pm 1.42$ & & $6.48 \pm 3.89$ & \\
\hline mSIS 2 & $48.15 \pm 78.20$ & & $16.21 \pm 21.86$ & \\
\hline \multicolumn{5}{|c|}{ Hemoglobin, $g / d L$, mean \pm SD } \\
\hline mSIS 0 & $14.06 \pm 1.33$ & $p=0.058^{\mathrm{F}}$ & 8.4 & $p=0.136^{\mathrm{F}}$ \\
\hline mSIS 1 & $13.53 \pm 2.57$ & & $11.74 \pm 1.32$ & \\
\hline mSIS 2 & $11.06 \pm 2.75$ & & $10.37 \pm 1.72$ & \\
\hline \multicolumn{5}{|c|}{ Lenght of hospital stay, day, mean \pm SD } \\
\hline mSIS 0 & $4.63 \pm 1.50$ & $p=0.127^{\mathrm{H}}$ & 3 & $p=0.032$ \\
\hline mSIS 1 & $4.67 \pm 1.21$ & & $4 \pm 1.22$ & \\
\hline mSIS 2 & $6.17 \pm 1.47$ & & $5.64 \pm 1.33$ & \\
\hline \multicolumn{5}{|c|}{ Follow-up time, month, mean \pm SD } \\
\hline mSIS 0 & $32.89 \pm 27.89$ & $p=0.034^{\mathrm{H}}$ & 70.70 & $p=0.314^{\mathrm{H}}$ \\
\hline mSIS 1 & $18.62 \pm 13.83$ & & $13.57 \pm 9.56$ & \\
\hline mSIS 2 & $5.77 \pm 5.10$ & & $19.35 \pm 21.38$ & \\
\hline
\end{tabular}

X2 chi-square test, $F$ one-way ANOVA test, $H$ Kruskal-Wallis test

long-term results of limb perfusion method according to the mSIS scoring system in cutaneous melanoma cases with in-transit metastasis. While planning this study, the patients were evaluated in two steps. The $\mathrm{mSIS}$ scores were calculated before and after the perfusion. Thus, the effects of the mSIS scoring system on the post-operative early and long-term outcomes of both the disease and the perfusion process were evaluated separately. The literature review has shown that there is no study investigating the effects of SIS or mSIS on the outcomes in patients with CM or patients undergoing limb perfusion. It has been further observed that there is no study focusing on predicting the outcomes of limb perfusion. All of the studies are on the contribution of perfusion to OS and disease-free survival (DFS) [10,
19]. Therefore, this is the first study in this regard as the systemic inflammatory response is utilized and is a two-step study.

We built the design of the present study on mSIS. It could have been performed only using SIS, without modification. However, we are aware of the fact that the accuracy rate of a test in which multiple parameters are used together is always higher than the univariate analysis. The best example of this is the combined use of gamma-probe and blue dye in sentinel lymph node sampling; which increases the sensitivity from 40 to 90-98\%. Furthermore, Chang et al. reported in their article published in 2015 that compared to SIS, mSIS provided more accurate results in predicting prognosis in patients with renal cell carcinoma [13]. The important issue here is which factor should be added to the traditional inflammatory parameters for mSIS. While Chang et al. used Alb for modification, Huang He et al. used CRP [20]. Both of these two parameters have been recently been added to the SIS scoring system. Therefore, they have no absolute superiority over each other. We also preferred to use Alb in this study because intransit metastases were large and ulcerated in some of the patients. This would lead to an increase in CRP levels and erroneous classification in mSIS groups. Although Alb is a nutritional indicator, it is recognized as a factor affecting the OS in various types of cancer. It has been confirmed that Alb can protect cell growth and DNA replication and exert antioxidant effects on carcinogens [21]. In many types of cancer (particularly in the gastrointestinal region) and in the presence of chronic systemic inflammation, the ability of the liver to synthesize Alb is reduced, causing hypoalbuminemia development [22]. Malnutrition may also contribute to the decrease in Alb levels, leading to the weakening of the cellular and humoral immune system and thus to errors in the anti-tumor mechanisms. However, since the rate of inadequate oral intake is very low in $\mathrm{CM}$ located in the limb, the risk of malnutrition is lower than in other types of cancer. In light of this data, we believe the choice of Alb is the right decision for the present study.

There is no consensus about which inflammatory parameters to use in SIS. There are studies using parameters such as lymphocyte, neutrophil, monocyte, and thrombocyte separately whereas their ratio combinations to each other have also been used in many studies $[23,24]$. We preferred to use LMR in the present study. Lymphocytes are involved in anticancer immunity by preventing the proliferation, invasion, and metastasis of tumor cells. Low lymphocyte levels are responsible for insufficient immune response against tumor cells [25]. Unlike lymphocytes, monocyte contributes to the 
Table 4 Effect of pre-perfusion and post-perfusion mSIS on surgical complications and local toxicity

\begin{tabular}{|c|c|c|c|c|c|c|c|c|c|c|}
\hline & \multicolumn{5}{|c|}{ Clavien-Dindo classification } & \multirow[t]{2}{*}{$p$ value } & \multicolumn{3}{|c|}{ Wierberdink classification } & \multirow[t]{2}{*}{$p$ value } \\
\hline & Grade 1 & Grade 2 & Grade 3 & Grade 4 & Grade 5 & & Grade 1 & Grade 2 & Grade 3 & \\
\hline \multicolumn{11}{|c|}{ Pre-perfusion } \\
\hline mSIS 0 & 6 & 1 & 0 & 1 & 0 & \multirow[t]{3}{*}{$0,188^{x^{2}}$} & 2 & 5 & 1 & \multirow[t]{3}{*}{$0.786^{x^{2}}$} \\
\hline mSIS 1 & 4 & 0 & 0 & 1 & 1 & & 0 & 5 & 1 & \\
\hline mSIS 2 & 2 & 2 & 2 & 0 & 0 & & 1 & 4 & 1 & \\
\hline \multicolumn{11}{|c|}{ Post-perfusion } \\
\hline mSIS 0 & 1 & 0 & 0 & 0 & 0 & \multirow[t]{3}{*}{$0,555^{\times 2}$} & 1 & 0 & 0 & \multirow[t]{3}{*}{$0.110^{x^{2}}$} \\
\hline mSIS 1 & 4 & 0 & 0 & 0 & 1 & & 1 & 4 & 0 & \\
\hline \multirow[t]{2}{*}{ mSIS 2} & 7 & 3 & 2 & 2 & 0 & & 1 & 10 & 3 & \\
\hline & \multicolumn{6}{|c|}{ Clavien-Dindo classification } & \multicolumn{4}{|c|}{ Wieberdink toxicity grading } \\
\hline Grade I & \multicolumn{6}{|c|}{$\begin{array}{l}\text { Any deviation from the normal post-operative course without need of interven- } \\
\text { tion }\end{array}$} & \multicolumn{4}{|c|}{ No visible effect } \\
\hline Grade II & \multicolumn{6}{|c|}{ Complication requiring pharmacological treatment } & \multicolumn{4}{|c|}{ Slight erythema and/or edema } \\
\hline Grade III & \multicolumn{6}{|c|}{ Complication requiring surgical,endoscopic, or radiological intervention } & \multicolumn{4}{|c|}{$\begin{array}{l}\text { Considerable erythema and/or edema with blister- } \\
\text { ing }\end{array}$} \\
\hline Grade IV & \multicolumn{6}{|c|}{ Life threatening complication requiring admission to intensive care unit } & \multicolumn{4}{|c|}{$\begin{array}{l}\text { Extensive epidermolysis and/or obvious damage to } \\
\text { deep tissues with a threatened or actual compart- } \\
\text { ment syndrome }\end{array}$} \\
\hline Grade V & \multicolumn{6}{|l|}{ Death } & \multicolumn{4}{|c|}{ Severe tissue damage necessitating amputation } \\
\hline
\end{tabular}

$x^{2}$ chi-square test

progression of tumor cells due to its transformation into the tumor-associated macrophages (TAMs) in the tumor microenvironment. Tumor-associated macrophages are responsible for tumor growth, angiogenesis, and metastasis [26]. In other words, high monocyte levels are an indicator of poor prognosis. Therefore, we used the ratio of two opposite parameters to each other. The cut-off value of this ratio was calculated based on the cut-off value determined in other mSIS studies because the present study has limited number of patients as in other studies on limb perfusion. Furthermore, the literature review has shown that the limb perfusion studies available do not use serum-based inflammatory parameters. During this selection, two different rates were observed. Cut-off value was accepted as 4.4 by Chang et al. while it was accepted as 3.4 by Lin et al. [13, 27]. In the preparation phase of the present study, when the cut-off value was accepted as 4.4, the pre-perfusion mSIS groups were observed not to be homogeneously distributed. However, when the ratio was taken as 3.4, this distribution was found to be homogeneous. Therefore, the cut-off value was accepted as 3.4 in the present study.

The correlation of pre- and post-perfusion mSIS with surgical complication and local toxicity was evaluated and no statistically significant correlation was observed between pre- and post-perfusion mSIS groups and these two types of complications. However, a detailed review of the data revealed that although there was no statistically significant correlation between the post-perfusion mSIS groups and complications, there were significant numerical differences. First of all, none of our patients had deep tissue damage, which was classified as grade IV or V based on the Wieberdink toxicity scale, and no amputation was needed. All grade II toxicities were observed in the mSIS 1 and 2 groups whereas grade III toxicity was detected only in the mSIS 2 group. There was no numerical difference in the distribution of pre-perfusion mSIS groups according to local toxicity classification. The patients were equally distributed in all three grades. Similarly, grade III, IV, and V complications, which are considered to be more severe in Clavien-Dindo complication classification, were observed to develop in the mSIS 1 and $\mathrm{mSIS} 2$ groups. All grades showed equal distribution in pre-perfusion mSIS groups. We believe that it would be meaningless if pre-perfusion mSIS groups affected local toxicity and surgical complication as these complications occur after perfusion and therefore we would like to mention that the authors of the present study are highly satisfied with these findings. We do not expect the data detected in the preoperative period to affect the incidence of complications. The incidence of post-operative complications is higher in patients with malnutrition and lower Alb levels [28]. However, low Alb levels are less likely in cutaneous melanoma arising from the limbs. Furthermore, since the perfusion procedure is not an urgent intervention, it may be delayed until adequate albumin replacement is provided. In the present study, the mean pre-perfusion Alb values of the patients was 


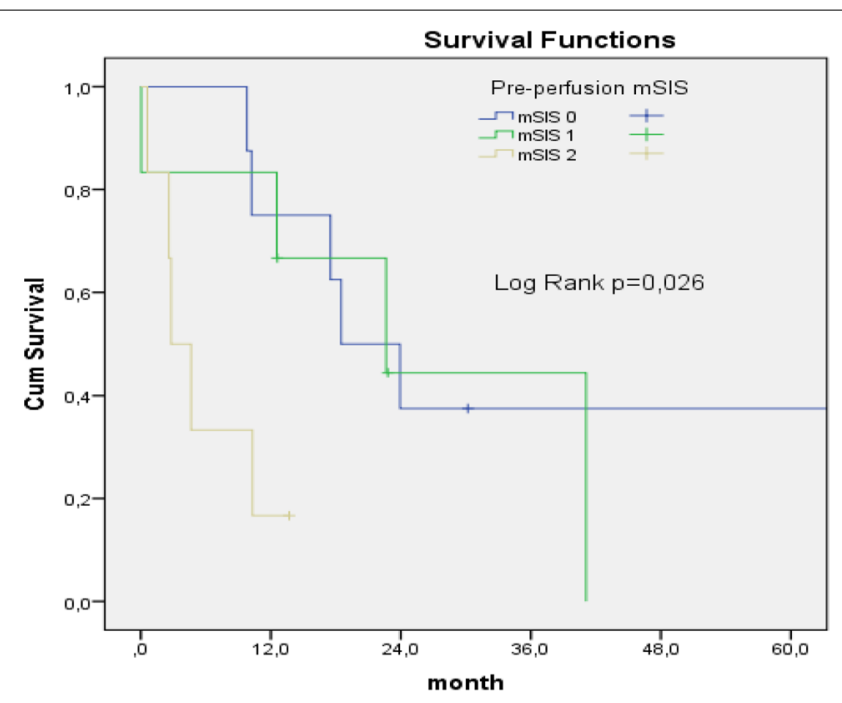

\begin{tabular}{|c|c|c|c|c|c|}
\hline \multirow{3}{*}{ Patients at risk } & \multirow{3}{*}{$\begin{array}{l}\text { Number } \\
\text { of } \\
\text { events }\end{array}$} & \multicolumn{4}{|c|}{ Median } \\
\hline & & \multirow{2}{*}{$\begin{array}{l}\text { Estimate } \\
\text { overall } \\
\text { survival }\end{array}$} & \multirow{2}{*}{$\begin{array}{l}\text { Standart } \\
\text { deviation }\end{array}$} & \multicolumn{2}{|c|}{ 95\% Confidence interval } \\
\hline & & & & Lower bound & Upper bound \\
\hline Pre-perfusion mSISO & $5 / 8$ & 18.5 & 4.549 & 9.584 & 27.416 \\
\hline Pre-perfusion mSIS 1 & $4 / 6$ & 22.633 & 10.067 & 2.903 & 42.364 \\
\hline Pre-perfusion mSIS 2 & $5 / 6$ & 2.8 & 1.245 & 0.359 & 5.241 \\
\hline
\end{tabular}

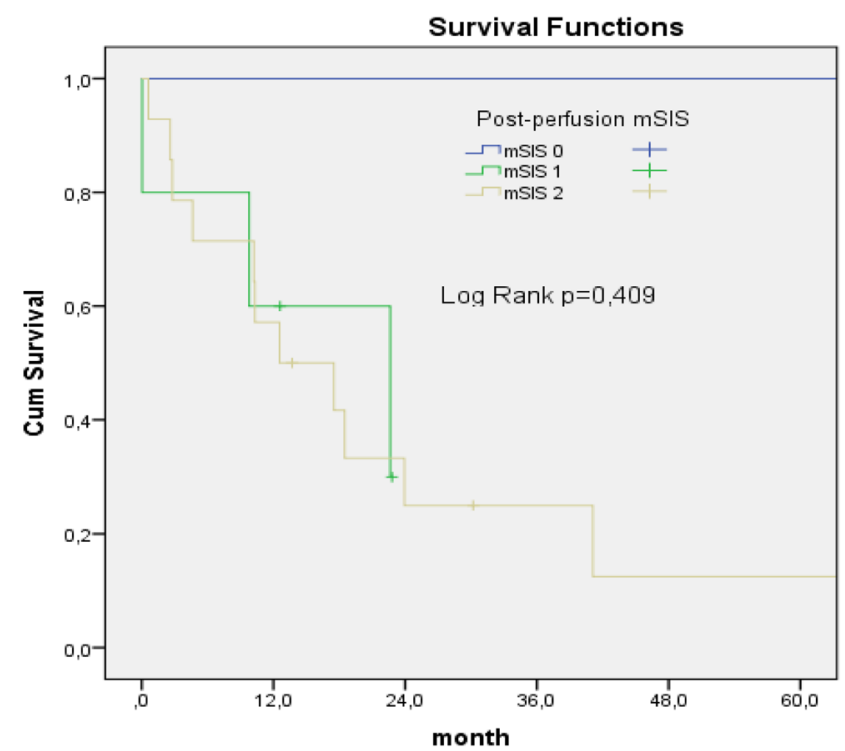

Fig. 1 Kaplan-Meier analysis for OS according to The pre-perfusion mSIS and post-perfusion mSIS

3.80. Fortunately, both types of complications were more closely associated with the post-perfusion mSIS groups because the mSIS system used in this study contained Alb, lymphocytes, and monocytes. Furthermore, as mentioned earlier, Alb is a negative acute phase reactant besides being a malnutrition indicator. Therefore, insufficient immune response may occur in the presence of low Alb levels. The authors have no doubt that the statistically insignificant but numerically significant finding will be statistically significant with a sufficient number 
Table 5 Univariate and multivariate analysis of pre-perfusion and post-perfusion mSIS for overall survival

\begin{tabular}{|c|c|c|c|c|}
\hline \multirow[t]{2}{*}{ Characteristics } & \multicolumn{2}{|l|}{ Univariate analysis } & \multicolumn{2}{|l|}{ Multivariate analysis } \\
\hline & HR (95\% Cl) & $p$ value & HR (95\% Cl) & $p$ value \\
\hline \multicolumn{5}{|l|}{ Pre-perfusion } \\
\hline \multicolumn{5}{|l|}{ mSIS 0} \\
\hline mSIS 1 & $0.162(0.036-0.729)$ & 0.018 & $0.018(0.00-4.023)$ & 0.146 \\
\hline mSIS 2 & $0.223(0.049-1.019)$ & 0.053 & $0.074(0.005-1.131)$ & 0.061 \\
\hline \multicolumn{5}{|l|}{ Pre-perfusion } \\
\hline Albumin $<4.0 \mathrm{~g} / \mathrm{dL}$ & $2.559(0.870-7.526)$ & 0.088 & $0.364(0.013-10.491)$ & 0.556 \\
\hline \multicolumn{5}{|l|}{ Albumin $\geq 4.0 \mathrm{~g} / \mathrm{dL}$} \\
\hline \multicolumn{5}{|l|}{ Pre-perfusion } \\
\hline \multicolumn{5}{|l|}{ LMR $<3.4$} \\
\hline$L M R \geq 3.4$ & $2.027(0.622-6.606)$ & 0.241 & $0.269(0.023-3.151)$ & 0.296 \\
\hline \multicolumn{5}{|l|}{ Post-perfusion } \\
\hline \multicolumn{5}{|l|}{ mSIS 0} \\
\hline \multicolumn{5}{|l|}{ mSIS 1} \\
\hline mSIS 2 & $0.938(0.253-3.474)$ & 0.924 & $0.933(0.140-6.228)$ & 0.943 \\
\hline \multicolumn{5}{|l|}{ Post-perfusion } \\
\hline Albumin $<4.0 \mathrm{~g} / \mathrm{dL}$ & $26.558(0.013-$ & 0.397 & & \\
\hline Albumin $\geq 4.0 \mathrm{~g} / \mathrm{dL}$ & $52393.2)$ & & & \\
\hline \multicolumn{5}{|l|}{ Post-perfusion } \\
\hline \multicolumn{5}{|l|}{$\mathrm{LMR}<3.4$} \\
\hline$L M R \geq 3.4$ & $1.374(0.452-4.172)$ & 0.575 & $0.994(0.200-4.927)$ & 0.994 \\
\hline
\end{tabular}

of patients. This difference in complication rates led to a statistically significant difference in the length of stay in the post-perfusion mSIS groups $(p=0.032)$. The length of stay was longer in the post-perfusion mSIS 2 group. This outcome causes a delay in returning to daily life after surgery. Adequate albumin support and appropriate antibiotic therapy in the pre-perfusion period may decrease $\mathrm{mSIS}$ value. Thus, a stronger immune response will occur and complication rates will decrease. Moreover, the decrease in complication rates will shorten the length of stay and allow patients to return to their daily lives earlier. This will ensure that the socio-economic losses of the patients are minimum.

Finally, the effects of pre-and post-perfusion mSIS groups on OS were investigated. In contrast to local toxicity and surgical complications, both numerically and statistically significant correlations were found. There was no statistically significant difference between the OS curves of the post-perfusion mSIS groups whereas there was a significant correlation between the OS curves of the pre-perfusion mSIS groups $(0.409-0.026)$. As it is considered meaningless that local toxicity and complications are affected by the data in the pre-perfusion period, we would also consider it meaningless that the OS, a highly important outcome, was affected by post-perfusion data. It is unacceptable that Alb and hematological parameters that change after an hour of perfusion affect the life span of a person. In the study by Chang et al., who first introduced the mSIS concept, and in other similar mSIS studies, the data of the patients were analyzed based on the laboratory results obtained in the preoperative period [13, 14]. The OS rates of the pre-perfusion mSIS 1 and mSIS 2 groups were found to be lower than the mSIS 0 group. We also correlated this difference with univariate analysis. While HR was statistically significant in the mSIS 1 group, it was very close to statistical significance level in the mSIS 2 group (0.018-0.053). Similarly, Chang et al. and Lin et al. reported that OS decreased as mSIS increased in patients with renal cell cancer and stomach cancer, respectively [13, 27]. Compatible with their study, we attribute this result to increased monocyte levels and decreased lymphocyte and Alb levels as mSIS values increased. As stated before, high monocyte is responsible for metastasis and angiogenesis, while low Alb and lymphocyte are responsible for insufficient immune response. Therefore, early metastasis and recurrence are observed in patients with high $\mathrm{mSIS}$, which contributes negatively to the prognosis and survival.

This study has several limitations. Firstly, randomization could not be done because of its retrospective design and it may have been subject to selection bias. Furthermore, several patients were excluded as their data were not able to be reached. This caused a limitation in the number of patients. 
Secondly, limb perfusion is not a routine surgical procedure. As in HIPEC, it is not a method yet accepted by surgeons and oncologists. Although our clinic is one of the few experienced centers in Turkey in this regard, our patient population is not sufficient. The fact that patients with an indication for extremity perfusion are not referred to our clinic is another reason for the limited number of patients. For these reasons, our sample size could not reach the sufficient number of patients. In the analysis using $t$ test for study power, $95 \%$ accuracy rate and when effect size conventions 0.5 was selected, the minimum sample size was 34 patients for correlation analysis and 184 patients according to Wilcoxon and Mann-Whitney U test. However, as we have seen in other studies, single-center studies on ILP have low patient numbers. Therefore, multicenter studies rather than a single center are needed for ILP.

\section{Conclusion}

In conclusion, the mSIS values calculated in the pre-perfusion period can give an opinion about the OS of the patients whereas post-perfusion mSIS values may predict potential surgical complications and local toxicities. Sufficient Alb replacement and appropriate antibiotic therapy after limb perfusion may prevent the development of potential complications. Thus, patients can return to their daily lives earlier and socio-economic losses may be kept to a minimum.

\begin{abstract}
Abbreviations
mSIS: Modified systemic inflammatory scoring; CM: Cutaneous melanoma; NLR: Neutrophil to lymphocyte ratio; LMR: Lymphocyte to monocyte ratio; CRP: C-reactive protein; Alb: Albumin; ILP: Isolated limb perfusion; HIPEC: Hyperthermic intraperitoneal chemotherapy; OS: Overall survival; AJCC: American Joint Committee on Cancer; NCCN: National Comprehensive Cancer Network; APPs: Acute-phase protein.
\end{abstract}

\section{Acknowledgements}

We are grateful to all patients and doctors contributed to this paper.

\section{Authors' contributions}

Şevket Barış Morkavuk: manuscript editing, statistical analysis, and preparation. Serdar Çulcu: quality control of data and algorithms. Ebru Esen: manuscript review. Ali Ekrem Unal: study concepts and design. All authors read and approved the final manuscript.

\section{Funding}

There is no funding and other support.

\section{Availability of data and materials}

The datasets used and/or analyzed during the current study are available from the corresponding author on reasonable request.

\section{Declarations}

Ethics approval and consent to participateThis study was reviewed and approved by the Ethics Committee of the Ankara City Hospital.Consent for publication

As the present study only collected retrospective clinical data and does not pose a risk to the participants, written informed consent was not required.

\section{Competing interests}

All authors declare that they have no competing interests.

\section{Author details}

${ }^{1}$ Department of Surgical Oncology, Ankara City Hospital, Ankara, Turkey. ${ }^{2}$ Department of Surgical Oncology, Dr. Abdurrahman Yurtaslan Research and Training Hospital, Ankara, Turkey. ${ }^{3}$ Department of Surgical Oncology, Ankara Gülhane Research and Training Hospital, Ankara, Turkey. ${ }^{4}$ Department of Surgical Oncology, Ankara University Faculty of Medicine, Ankara, Turkey.

Received: 9 July 2021 Accepted: 1 November 2021

Published online: 16 November 2021

\section{References}

1. Williams PF, Olsen CM, Hayward NK, Whiteman DC. Melanocortin 1 receptor and risk of cutaneous melanoma: A meta-analysis and estimates of population burden. Int J Cancer. 2011;129(7):1730-40.

2. Miller AJ, Mihm MC Jr. Melanoma. N Engl J Med. 2006;355(1):51-65.

3. Viale PH. The American Cancer Society's facts \& figures: 2020 edition. J Adv Practition Oncol. 2020;11(2):135.

4. Mian R, Henderson MA, Speakman D, Finkelde D, Ainslie J, McKenzie A. Isolated limb infusion for melanoma: a simple alternative to isolated limb perfusion. Can J Surg. 2001;44(3):189.

5. Meier F, Will S, Ellwanger U, Schlagenhauff B, Schittek B, Rassner G, et al. Metastatic pathways and time courses in the orderly progression of cutaneous melanoma. Br J Dermatol. 2002;147(1):62-70.

6. Francken AB, Accortt NA, Shaw HM, Wiener M, Soong S-j, Hoekstra HJ, et al. Prognosis and determinants of outcome following locoregional or distant recurrence in patients with cutaneous melanoma. Ann Surg Oncol. 2008;15(5):1476-84.

7. Tronnier M, Semkova K, Wollina U, Tchernev G. Malignant melanoma: epidemiologic aspects, diagnostic and therapeutic approach. Wien Med Wochenschr. 2013;163(15):354-8.

8. Creech O Jr, Krementz E, Ryan RF, Winblad JN. Chemotherapy of cancer: regional perfusion utilizing an extracorporeal circuit. Ann Surg. 1958;148(4):616.

9. Thompson J, Lai D, Ingvar C, Kam P. Maximizing efficacy and minimizing toxicity in isolated limb perfusion for melanoma. Melanoma Res. 1994;4:45-50.

10. Moreno-Ramirez D, de la Cruz-Merino L, Ferrandiz L, Villegas-Portero R, Nieto-Garcia A. Isolated limb perfusion for malignant melanoma: systematic review on effectiveness and safety. Oncologist. 2010;15(4):416.

11. Balkwill F, Mantovani A. Inflammation and cancer: back to Virchow? Lancet. 2001;357(9255):539-45.

12. Kim EY, Lee JW, Yoo HM, Park CH, Song KY. The platelet-to-lymphocyte ratio versus neutrophil-to-lymphocyte ratio: which is better as a prognostic factor in gastric cancer? Ann Surg Oncol. 2015;22(13):4363-70.

13. Chang $Y$, An H, Xu L, Zhu Y, Yang Y, Lin Z, et al. Systemic inflammation score predicts postoperative prognosis of patients with clear-cell renal cell carcinoma. Br J Cancer. 2015;113(4):626-33.

14. Suzuki Y, Okabayashi K, Hasegawa H, Tsuruta M, Shigeta K, Kondo T, et al. Comparison of preoperative inflammation-based prognostic scores in patients with colorectal cancer. Ann Surg. 2018;267(3):527-31.

15. Clavien P-A, Sanabria JR, Strasberg SM. Proposed classification of complications of surgery with examples of utility in cholecystectomy. Surgery. 1992;111(5):518-26.

16. Wieberdink J, Benckhuysen C, Braat R, Van Slooten E, Olthuis G. Dosimetry in isolation perfusion of the limbs by assessment of perfused tissue volume and grading of toxic tissue reactions. Eur J Cancer Clin Oncol. 1982;18(10):905-10

17. Jemal A, Saraiya M, Patel P, Cherala SS, Barnholtz-Sloan J, Kim J, et al. Recent trends in cutaneous melanoma incidence and death rates in the United States, 1992-2006. J Am Acad Dermatol. 2011;65(5):S17 e1-S. e1.

18. Ekwueme DU, Guy GP Jr, Li C, Rim SH, Parelkar P, Chen SC. The health burden and economic costs of cutaneous melanoma mortality by race/ethnicity-United States, 2000 to 2006. J Am Acad Dermatol. 2011;65(5):S133 e1-S. e12.

19. Chin-Lenn L, Temple-Oberle C, McKinnon JG. Isolated limb infusion: efficacy, toxicity and an evolution in the management of in-transit melanoma. Plastic Surg. 2015;23(1):25-30. 
20. Huang H, Chen LM, Fang XJ, Guo CC, Lin XP, Hong HM, et al. Prognostic value of the modified systemic inflammation score in patients with extranodal natural killer/T-cell lymphoma. Front Pharmacol. 2020;11:1549.

21. Arroyo V, García-Martinez R, Salvatella X. Human serum albumin, systemic inflammation, and cirrhosis. J Hepatol. 2014;61 (2):396-407.

22. Geng Y, Shao Y, Zhu D, Zheng X, Zhou Q, Zhou W, et al. Systemic immuneinflammation index predicts prognosis of patients with esophageal squamous cell carcinoma: a propensity score-matched analysis. Sci Rep. 2016:6(1):1-9.

23. Eroglu A, Akbulut S. The role of pretreatment neutrophil to lymphocyte ratio and platelet to lymphocyte ratio in the diagnosis of breast cancer: predicting lymph node metastasis. World J Oncol. 2013;4(6):262.

24. Okugawa Y, Toiyama Y, Yamamoto A, Shigemori T, Ide S, Kitajima T, et al. Lymphocyte-C-reactive protein ratio as promising new marker for predicting surgical and oncological outcomes in colorectal cancer. Ann Surg. 2020;272(2):342-51.
25. Dunn GP, Old LJ, Schreiber RD. The immunobiology of cancer immunosurveillance and immunoediting. Immunity. 2004;21(2):137-48.

26. Pollard JW. Trophic macrophages in development and disease. Nat Rev Immunol. 2009;9(4):259-70.

27. Lin J-X, Lin J-P, Xie J-W, Wang J-b, Lu J, Chen Q-Y, et al. Prognostic importance of the preoperative modified systemic inflammation score for patients with gastric cancer. Gastric Cancer. 2019;22(2):403-12.

28. Labgaa I, Joliat G-R, Kefleyesus A, Mantziari S, Schäfer M, Demartines N, et al. Is postoperative decrease of serum albumin an early predictor of complications after major abdominal surgery? A prospective cohort study in a European centre. BMJ Open. 2017;7(4):e013966.

\section{Publisher's Note}

Springer Nature remains neutral with regard to jurisdictional claims in published maps and institutional affiliations.
Ready to submit your research? Choose BMC and benefit from:

- fast, convenient online submission

- thorough peer review by experienced researchers in your field

- rapid publication on acceptance

- support for research data, including large and complex data types

- gold Open Access which fosters wider collaboration and increased citations

- maximum visibility for your research: over $100 \mathrm{M}$ website views per year

At BMC, research is always in progress.

Learn more biomedcentral.com/submissions 